\title{
Penentuan Frekuensi Natural Dan Arah Pergerakan Gelombang (Studi Kasus: Jembatan Soekarno Hatta Kota Malang)
}

\author{
Siti Maulidiyaa*, Ruslia \\ aJurusan Fisika, Fakultas Sains dan Teknologi, UIN Maulana Malik Ibrahim \\ Malang
}

KATA K UNCI

Jembatan

Frekuensi

Natural

Vibrasi

Gelombang

\begin{abstract}
A B S T R A K
Penelitian ini bertujuan untuk mengetahui nilai frekuensi natural dan arah pergerakan gelombang dari jembatan Soekarno Hatta kota Malang. Perekaman data penelitian menggunakan seismometer portable tipe TDL 303 S (3 komponen) dengan delapan titik pengukuran di sepanjang sisi jembatan. Data hasil perekaman tersebut diolah dengan menggunakan software Geopsy. Analisa data yang digunakan merupakan analisa HVSR dan analisa Particle motion. Analisa HVSR menghasilkan nilai frekuensi dominan dan amplifikasi gelombang. Analisa particle motion menghasilkan plot arah pergerakan gelombang. Berdasarkan analisa data yang dilakukan disimpulkan bahwa nilai frekuensi dominan/frekuensi natural ( $f_{0}$ ) dari jembatan yaitu berkisar 0,62 sampai 4,34 Hz yang menunjukkan bahwa jembatan sudah tidak layak digunakan sebagai sarana transportasi. Analisa particle motion secara kuantitatif menunjukkan arah pergerakan gelombang ke segala arah baik secara vertikal ataupun secara NS-EW
\end{abstract}

KE YWOR D S

Bridge

Natural

Frequency

Vibration

Wave

\begin{abstract}
A B S T R A C T
This study aims to determine natural frequency value of wave and its direction of movement of the bridge Soekarno Hatta town of Malang. Research data using a seismograph recording portable type TDL 303 S (3 components) with an eight-point measurement along the side of the bridge. Its results were processed using the software Geopsy. Analysis of the data used is the HVSR analysis and analysis of Particle motion. HVSR analysis showes values dominant frequency and wave amplification. Analysis of particle motion generates the plot direction of wave propagation. Based on the data analysis it can be concluded that the dominant frequency value/natural frequency $\left(f_{0}\right)$ of the bridge is ranged from 0,62 to $4,34 \mathrm{~Hz}$ which indicates that the bridge is not feasible to use as a means of transportation. Analysis of particle motion quantitatively indicate direction movement of the waves in all directions either vertically or NS-EW.
\end{abstract}

TERSEDIA ONLINE

1 Februari 2017

\section{Pendahuluan}

Semua benda yang memiliki massa dan elastisitas mampu untuk bergetar. Besarnya frekuensi natural suatu bahan yang bergetar secara transversal sangat dipengaruhi oleh modulus elastisitas bahan, dimensi/geometri (luas penampang, panjang), density, dan gaya aksi yang bekerja pada bahan. Jadi setiap material yang dikenai gaya aksi berupa gaya tarik dengan besar yang berbeda, jika digetarkan secara transversal akan menghasilkan frekuensi alami yang berbeda.

Getaran yang terjadi karena rangsangan gaya luar disebut getaran paksa. Jika rangsangan

*Corresponding author: Jurusan Fisika, Fakultas Sains dan Teknologi, UIN Malang; Email address: maulid.siti@gmail.com; rusli@fis.uin-malang.ac.id Published by FMIPA UNSRAT (2017) 
tersebut berosilasi, maka sistem dipaksa untuk bergetar pada frekuensi rangsangan. Jika frekuensi rangsangan sama dengan salah satu frekuensi natural sistem, maka akan didapat resonansi, dan osilasi besar yang berbahaya mungkin terjadi. Kerusakan pada struktur besar seperti jembatan, gedung atau sayap pesawat terbang, merupakan kejadian menakutkan yang disebabkan resonansi. Jadi, perhitungan frekuensi natural merupakan hal penting yang utama dalam pelajaran getaran (Thomson, 1986). Frekuensi alami struktur adalah frekuensi dari struktur yang secara alami cenderung untuk bergetar jika struktur ini terkena gangguan. Nilai frekuensi alami ini dapat digunakan sebagai pedoman apakah suatu struktur mengalami resonansi atau tidak. Suatu struktur akan mengalami resonansi apabila nilai frekuensi beban yang diterima struktur mendekati atau sama dengan frekuensi alaminya (Wahyuni, 2010).

Gelombang adalah getaran yang merambat melalui medium. Namun, tidak semua gelombang memerlukan medium gelombang yang memerlukan medium perambatan disebu gelombang mekanik, contohnya; gelombang permukaan air, gelombang bunyi. Gelombang yang tidak memerlukan medium perambatan disebut gelombang elektromagnetik, contohnya; gelombang cahaya, gelombang radio.

Gelombang seismik adalah gelombang yang menjalar di dalam bumi. Gelombang seismik timbul akibat adanya gempa bumi atau ledakan. Gelombang seismik diukur dengan menggunakan seismometer. Gelombang seismik merupakan gelombang yang menjalar di dalam bumi yang disebabkan karena adanya deformasi struktur di bawah bumi akibat adanya tekanan ataupun tarikan karena sifat keelastisitasan bumi. Gelombang ini membawa energi kemudian menjalarkan ke segala arah di seluruh bagian bumi (Hendrajaya, 1990).

\section{Metode}

Alat yang digunakan untuk merekam gelombang yaitu seismometer 3 komponen adalah sebuah seismometer yang memiliki 3 buah sensor dan mampu merekam gelombang gelombang gempa yang datang dari berbagai arah. Komponen sensor pada seismometer 3 komponen antara lain:

1. Sensor Komponen Vertikal Atas - Bawah (Updown, UD); sensor ini merekam gelombang gempa yang arah partikelnya bergerak dalam arah atas bawah.

2. Sensor Komponen Horizontal Utara - Selatan (North - South, NS); sensor ini merekam gelombang gempa yang arah partikelnya bergerak dalam arah Utara - Selatan atau yang mewakili arah ini.

3. Sensor komponen Horizontal Timur - Barat (East - West, EW); sensor ini merekam gelombang gempa yang arah partikelnya bergerak dalam arah Timur - Barat atau yang mewakili arah ini (Afnimar, 2009).
Teknik HVSR (Horizontal to Vertical Fourier Amplitude Spectral Rasio) pada analisis mikrotremor telah digunakan secara luas untuk studi efek local dan mikrozonasi. Selain sederhana dan bisa dilakukan kapan dan dimana saja, teknik ini juga mampu mengestimasi frekuensi resonansi secara langsung tanpa harus mengetahui struktur kecepatan gelombang geser dan kondisi geologi bawah permukaan lebih dulu. Menurut Nakamura bahwa metode HVSR untuk analisis mikrotremor bisa digunakan untuk memperoleh frekuensi natural sedimen (Aini, 2012).

Jembatan merupakan sarana prasarana umum yang penting. Jembatan dapat menghubungkan satu daerah dengan daerah lain sehingga pentingnya jembatan ini untuk mobilitas suatu daerah. Salah satu jembatan yang ada dikota Malang yaitu jembatan Soekarno-Hatta, jembatan ini berdiri sejak tahun 1981 merupakan jembatan yang mempunyai tingkat mobilitas tinggi, merupakan jembatan yang sering dilalui oleh masyarakat Malang pada khususnya dan daerah sekitar Malang pada umumnya (Budio dkk, 2010).

Pengambilan data di jembatan Soekarno Hatta dengan 8 titik pengukuran, 4 titik sebelah kiri dan 4 titik disebelah kanan seperti gambar 3.2. Setiap titik pengukurun di ambil data dengan durasi 30 menit.

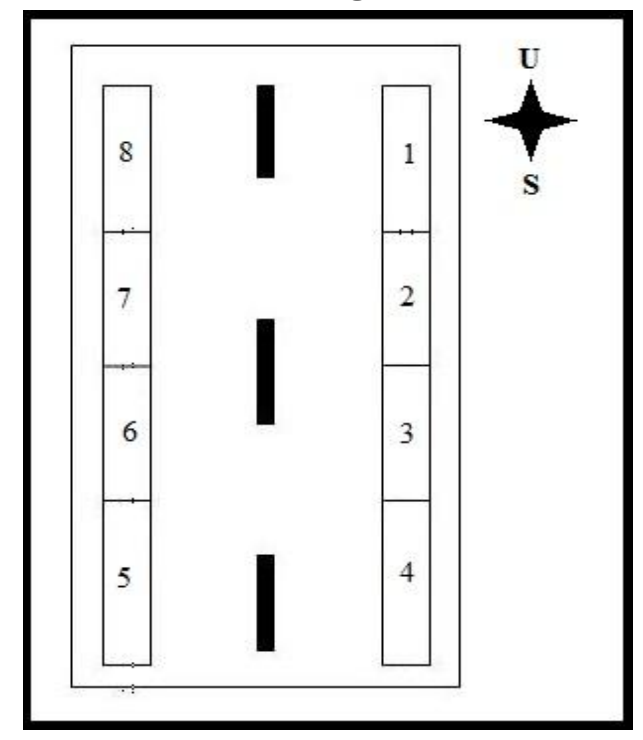

Gambar 1. Pengambilan Data Penelitian di Jembatan

Data yang telah diambil dan dilakukan pengolahan menggunkakan perangkat keras yang meliputi satu set komputer yang dilengkapi dengan perangkat lunak yang terdiri dari program geopsy. Data sinyal yang tersimpan di kartu memori alat, kemudian diubah dalam format ASCII dengan software datapro agar bisa terbaca oleh program geopsy. Data dalm bentuk tersebut diolah menggunakan software geopsy. Pada software geopsy dilakukan pemilihan windows. Pemilihan windows ini adalah proses pemilihan antara sinyal tremor dan event transient. Dan dilakukan analisa 
HVSR dan analisa Particle motion. Dari analisa HVSR didapatkan nila frekuensi dominan dan amplifikasi pada setiap titik pengukuran. Pada analisa particle motion didapat plot pergerakan partikel dari gelombang.

\section{Hasil dan Pembahasan \\ Analisa HVSR}

Berdasarkan hasil pengolahan data menggunakan software geopsy, menggunakan analisa HVSR dan particle motion. Dengan menggunakan analisa HVSR dapat ditentukan nilai frekuensi dominan dan amplifikasi, Adapun data hasil analisa HVSR sebagai berikut:

Tabel 1 data hasil analisa HVSR

\begin{tabular}{|c|c|c|c|c|c|c|}
\hline $\begin{array}{c}\text { Titik } \\
\text { pengukuran }\end{array}$ & Bujur & Lintang & $\begin{array}{c}\text { Waktu } \\
\text { pengukuran } \\
\text { (WIB) }\end{array}$ & $\begin{array}{c}\mathrm{h} \\
\text { (dpl) }\end{array}$ & $\begin{array}{c}F_{0} \\
\text { (frekuensi } \\
\text { dominan) }\end{array}$ & $\begin{array}{c}\mathbf{A} \\
\text { (amplifikasi) }\end{array}$ \\
\hline Titik 1 & 112,61622 & 7,94905 & $\begin{array}{l}18.30- \\
19.00\end{array}$ & 502 & 0.65 & 4.34 \\
\hline Titik 2 & 112,61604 & 7.94931 & $\begin{array}{l}19.06- \\
19.36\end{array}$ & 502 & 0.68 & 3.18 \\
\hline Titik 3 & 112,61586 & 7.94953 & $\begin{array}{c}19.44- \\
20.14\end{array}$ & 501 & 0.69 & 1,68 \\
\hline Titik 4 & 112.61563 & 7.94984 & $\begin{array}{l}2020- \\
20.40\end{array}$ & 501 & 4.36 & 4.29 \\
\hline Titik 5 & 112,61554 & 7,94976 & $\begin{array}{l}20.50- \\
2120\end{array}$ & 501 & 0.67 & 5,47 \\
\hline Titik 6 & 112,61576 & 7,94953 & $\begin{array}{l}2126- \\
2156 \\
\end{array}$ & 501 & 0.62 & 1,54 \\
\hline Ittik 7 & 112,616 & 7,94928 & $\begin{array}{l}2202- \\
2232\end{array}$ & 501 & 1,35 & 4,43 \\
\hline Titik 8 & 112,61616 & 7,949 & $\begin{array}{l}22.40- \\
23.10\end{array}$ & 500 & 0,68 & 3.21 \\
\hline
\end{tabular}

Hasil pengolahan data menggunakan software geopsy berupa spektrum HVSR. Salah satu hasilnya adalah gambar 2, menunjukkan garis putus-putus paling atas dan bawah merupakan standar deviasi untuk semua nilai rasio spektrum yang dihasilkan. Garis tanpa putus yang berada di tengah merupakan nilai rata-rata yang dihasilkan oleh analisis FFT dari seluruh nilai rasio $\mathrm{H} / \mathrm{V}$, sedangkan garis berwarna-warni merupakan kurva $\mathrm{H} / \mathrm{V}$ dari masing-masing window. Frekuensi natural diketahui dari puncak HVSR, dan nilai puncak HVSR adalah amplifikasi. Spektrum hasil analisa HVSR.

Nilai frekuensi dominan merupakan parameter yang sangat berguna dalam perencanaan dan pembangunan bangunan yang rentang terhadap gangguan vibrasi seperti gempa bumi, angin, kendaraan ataupun aktifitas manusia. Nilai frekuensi dominan (fo) yang dimiliki struktur bangunan seperti jembatan tidak boleh memiliki kesamaan dengan nilai frekuensi dominan ( $f_{0}$ ) yang dimiliki oleh gangguan vibrasi yang salah satunya aktifitas manusia karena akan mengalami resonansi jika fo dari kendaraan menyamai fo jembatan.

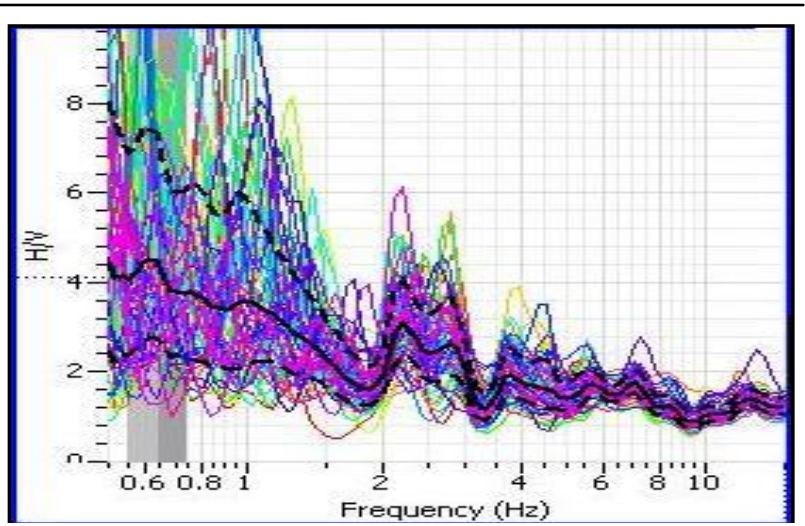

Gambar 2. Hasil Spektrum Analisa HVSR

Nilai frekuensi dominan dari pengolahan data tersebut memiliki nilai berkisar 0,62 sampai 4,34 $\mathrm{Hz}$. Nilai rata-rata frekuensi dominan berkisar 1.21 Hz. Nilai ini menunjukkan bahwa nilai frekuensi dominan dari bangunan adalah lebih dari $1 \mathrm{~Hz}$. Menurut SESAME European Research Project (2005), pada frekuensi tinggi 0.5 sampai $1-10 \mathrm{~Hz}$ menunjukkan terkait dengan aktifitas manusia (lalu lintas, mesin). Frekuensi natural kendaraannya yang melewati jembatan di atas $0,5 \mathrm{~Hz}$ akan mempengaruhi elastisitas jembatan, karena frekuensi natural jembatan yang diatas $1 \mathrm{~Hz}$ akan mengakibatkan resonansi pada jembatan tersebut. Frekuensi natural kendaraan dengan frekuensi natural yang hampir sama merupakan faktor yang mengakibatkan resonansi pada jembatan meskipun kecil.

Nilai puncak HV merupakan nilai amplifikasi dari titik pengukuran. Amplifikasi yaitu proses untuk meningkatkan kekuatan sinyal melalui amplitudo. Amplifikasi gelombang mengakibatkan kerusakan pada lapisan tanah, hal ini karena adanya gelombang yang terjebak di lapisan lunak, jika gelombang tersebut mempunyai frekuensi yang relatif sama, maka terjadi resonansi. Faktor amplifikasi dipengaruhi oleh densitas material dan kecepatan gelombang geser. Nilai puncak HVSR atau amplifikasi pada wilayah penelitian ini berkisar 1,54 sampai 5,47 yang berarti memiliki nilai yang cukup tinggi. Nilai amplifikasi pada wilayah penelitian menunjukkan nilai rata-rata berkisar 3 sampai 4. Nilai amplifikasi tertinggi pada titik pengukuran ke-5 yaitu berkisar 5,47. Titik pengukuran tersebut terletak pada jalan yang menuju ke arah jln. MT Haryono, lokasi tersebut sering terjadi tempat pemberhentian kendaraan yang memberi tekanan pada jembatan.

Kerusakan tinggi akan terjadi pada zona frekuensi dominan yang rendah dan nilai amplifikasi yang tinggi. Nilai amplifikasi tertinggi dengan frekuensi dominan terendah terdapat pada titik pengukuran ke-1 dan ke-5. Ini menunjukkan daerah rawan kerusakan pada titik pengukuran tersebut. Pada daerah titik pengukuran ke-1 merupakan daerah sisi sebelah apartemen Suhat, dan pada daerah titik pengukuran ke-5 merupakan daerah menuju JIn MT Haryono. Daerah tersebut 
merupakan daerah yang sering dijadikan tempat perhentian kendaraan. Apalagi daerah titik pengukuran ke-5 merupakan daerah untuk memutar arah atau menuju ke daerah Dinoyo yang sering menjadi daerah perhentian kendaraan yang padat.

\section{Analisa Particle Motion}

Jembatan Soekarno Hatta diibaratkan sebagai lapisan permukaan bumi. Getaran yang merambat bersumber dari kendaraan diibaratkan gelombang seismik Gelombang seismik tersebut direkam oleh seismometer. Gelombang tersebut akan melewati medium dengan material baja dan beton (komposit), gelombang seismik yang melewati medium tersebut merupakan gelombang longitudinal dan transversal.

Gelombang yang bergerak dari satu tempat ke tempat yang lain, akan diikuti pergerakan partikel gelombang tersebut searah, tegak lurus ataupun ke segala arah perambatannya dalam medium yang dilewati. Pergerakan partikel gelombang tersebut mempengaruhi medium yang dilewati yaitu jembatan tersebut.

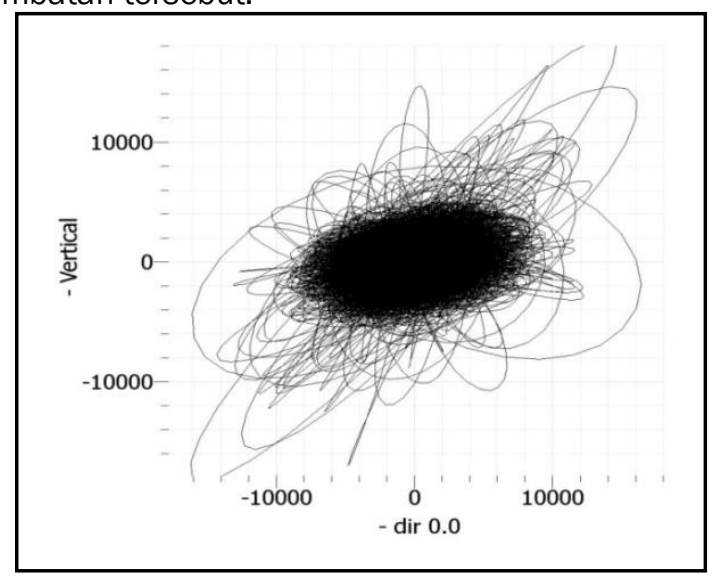

(1)

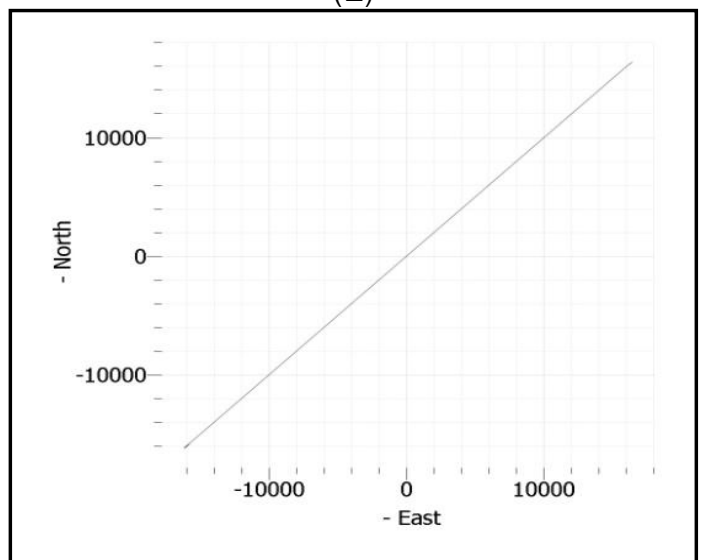

(2)

Gambar 3. Hasil analisa particle motion dengan geopsy pada titik pengukuran ke-1.

(1) arah vertikal. (2) arah timur laut-barat daya

Pada gambar 3 menunjukkan arah pergerakan partikel gelombang pada titik pengukuran 1 dominan ke arah vertikal dengan miring sedikit. Dari gambar tersebut menunjukkan bahwa frekuensi pergerakan ke arah vertikal lebih banyak daripada arah timur laut-barat daya. Garis hitam yang pekat tersebut menunjukkan daerah yang sering dilewati oleh gelombang.

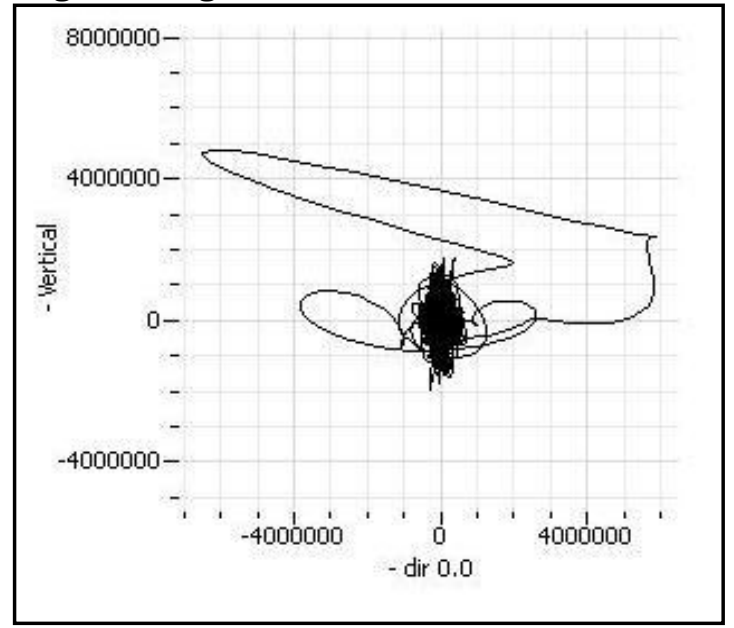

(1)

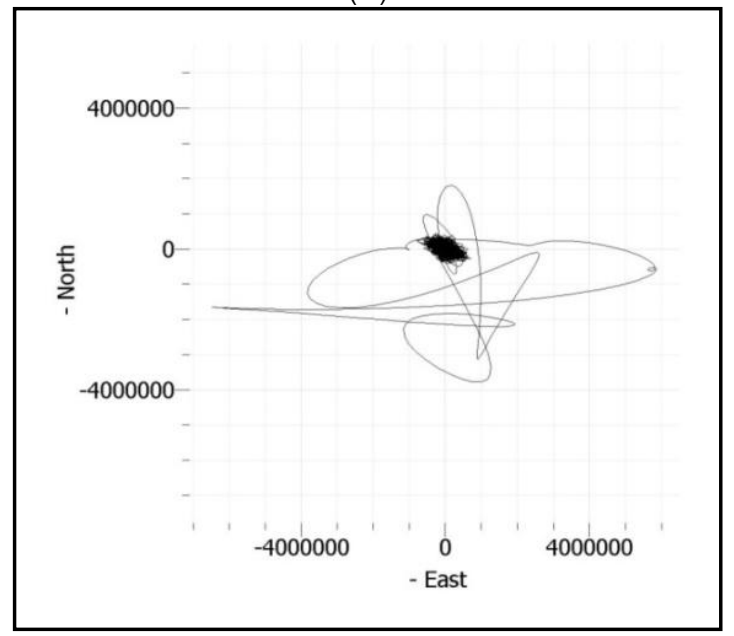

(2)

Gambar 4. Hasil analisa particle motion dengan geopsy pada titik pengukuran ke-2.

(1) Arah vertikal. (2) arah utara selatan

Pada gambar 4 (1) menunjukkan pergerakan partikel gelombang ke arah vertikal. Pada gambar yang 4 (2) menunjukkan ke arah utara selatan. Pada titik pengukuran ke-2 ini arah pergerakan partikel gelombang lebih dominan ke arah sejajar pada bidang vertikal.

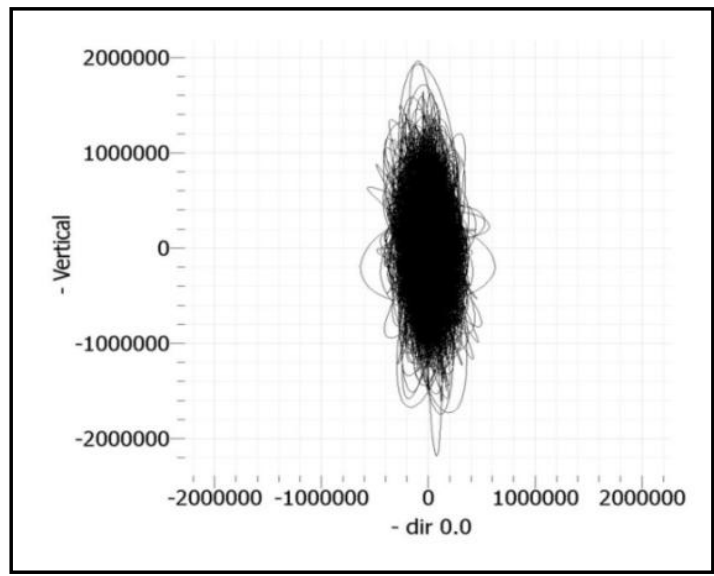

(1) 


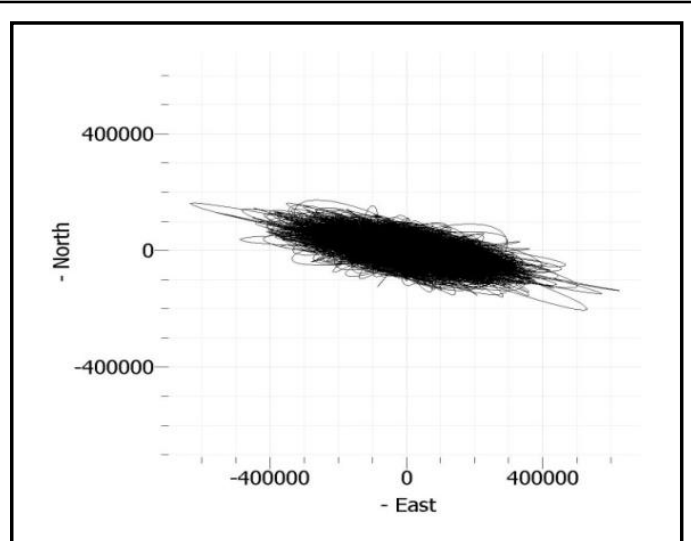

(2)

Gambar 5. Hasil analisa particle motion dengan geopsy pada titik pengukuran ke-3.

(1) Arah vertikal. (2) arah utara-selatan

Pada gambar 5 menunjukkan bahwa pergerakan partikel bergerak ke arah sejajar dengan bidang vertikal, walaupun ke arah utara-selatan pada jembatan frekuensi pergerakan partikel hampir sama namun lebih dominan ke arah sejajar bidang vertikal jembatan.

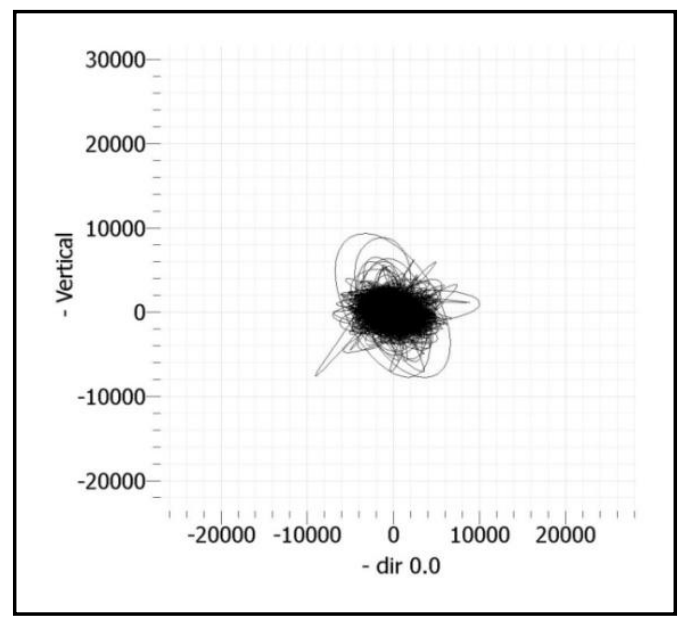

(1)

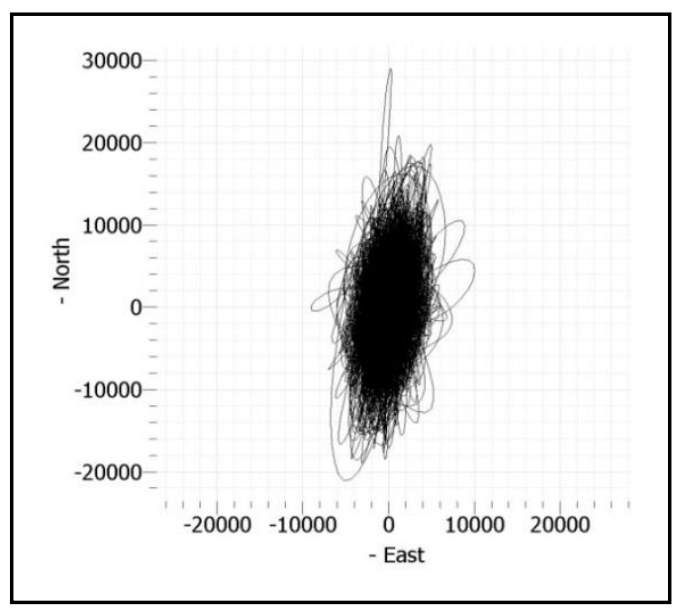

(2)

Gambar 6. Hasil analisa particle motion dengan geopsy pada titik pengukuran ke-4.

(1) Arah vertikal. (2) Arah timur-barat
Pada gambar 6 menunjukkan bahwa pergerakan partikel dominan pada arah ke timurbarat pada jembatan. Terlihat pada gambar tersebut frekuensi pergerakan partikel yang ke arah vertikal lebih kecil.

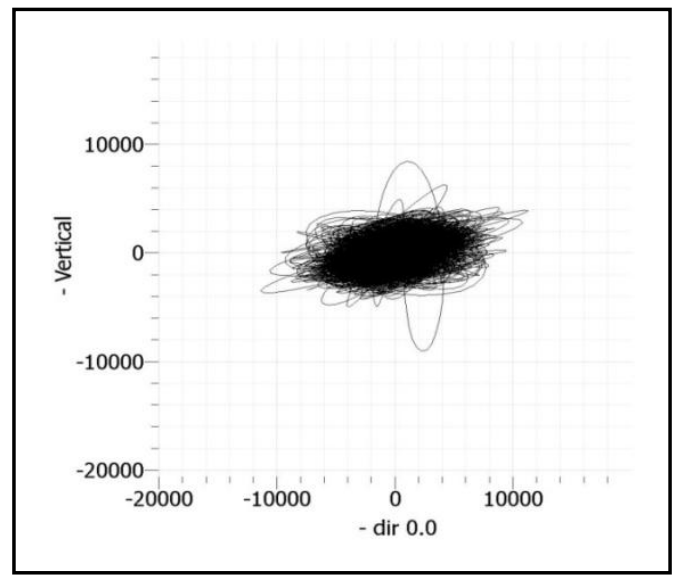

(1)

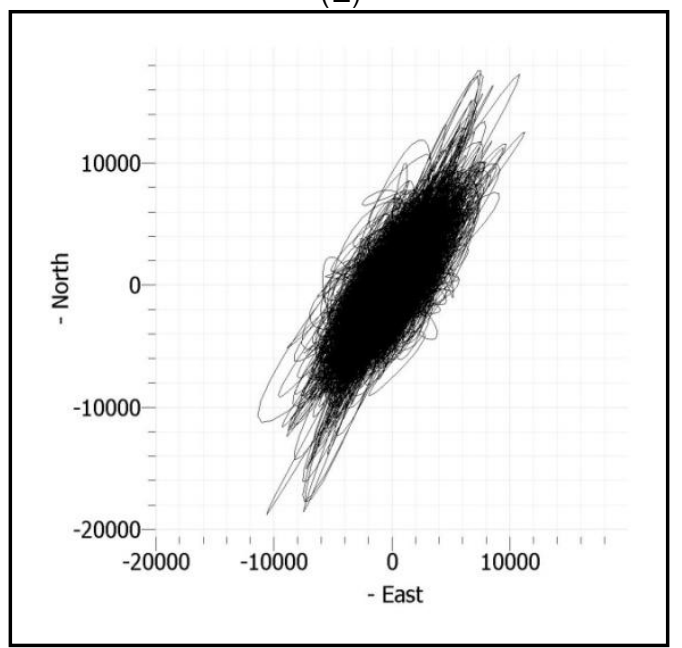

(2)

Gambar 7. Hasil analisa particle motion dengan geopsy pada titik pengukuran ke-5.

(1) Arah vertikal. (2) Arah timur barat

Pada gambar 7 menunjukkan arah pergerakan partikel pada titik pengukuran ke-5 bergerak ke arah timur barat, dilihat dari gambar tersebut frekuensi arah pergerakan partikel yang bergerak secara vertikal lebih kecil.

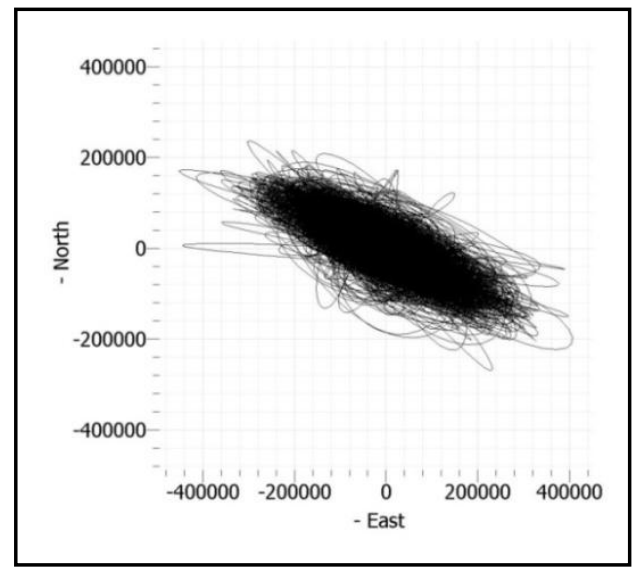

(1) 


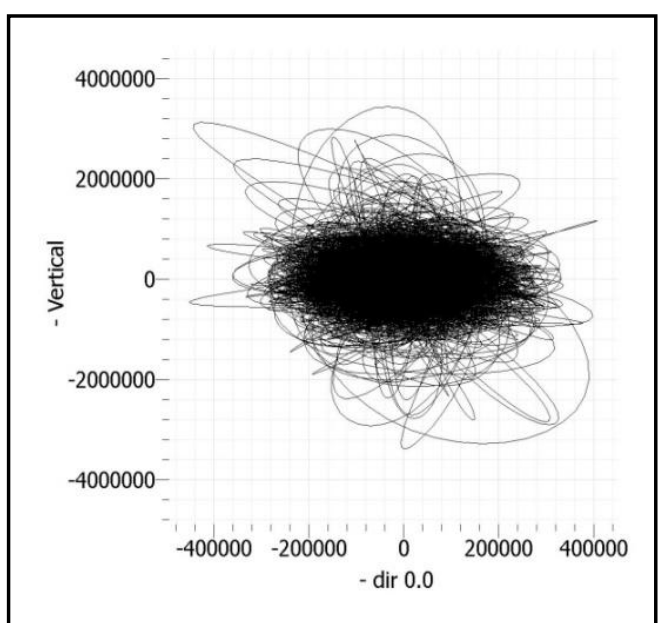

(2)

Gambar 8. Hasil analisa particle motion dengan geopsy pada titik pengukuran ke- 6 .

(1) arah utara selatan. (2) arah vertikal

Pada gambar 8 menunjukkan arah pergerakan partikel gelombang ke arah vertikal pada jembatan. Pada titik pengkuran ini terlihat arah pergerakan partikel dominan ke arah vertikal.

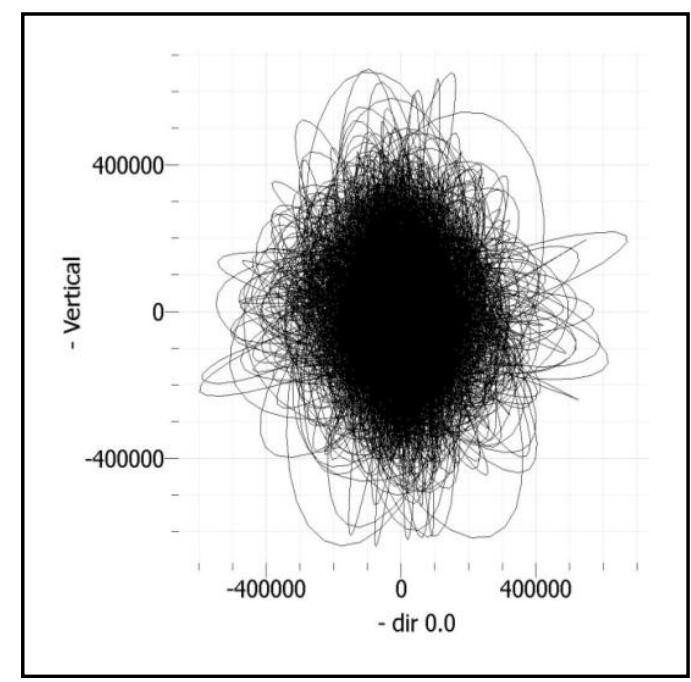

(1)

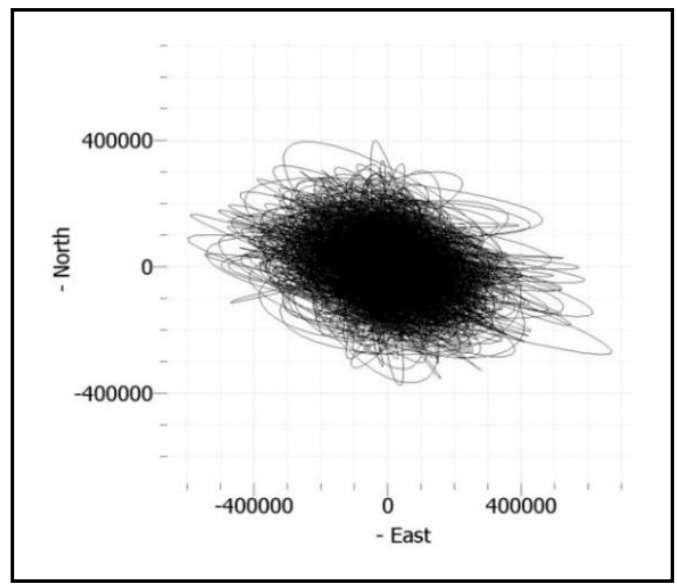

(2)

Gambar 9. Hasil analisa particle motion dengan geopsy pada titik pengukuran ke-7.

(1) Arah vertikal. (2) arah utara selatan
Pada gambar 9 menunjukkan arah pergerakan partikel gelombang pada titik pengukuran yang ke-7. Pada gambar tersebut menunjukkan arah pergerakan partikel bergerak sejajar dengan bidang vertikal pada jembatan lebih dominan.

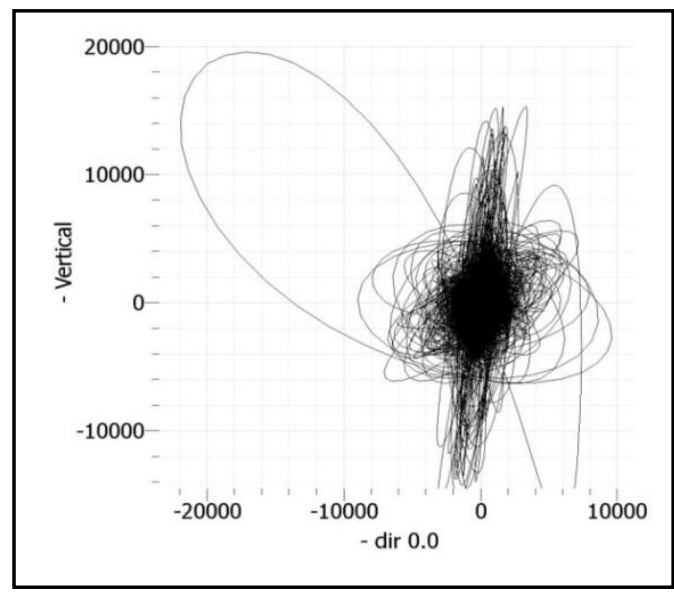

(1)

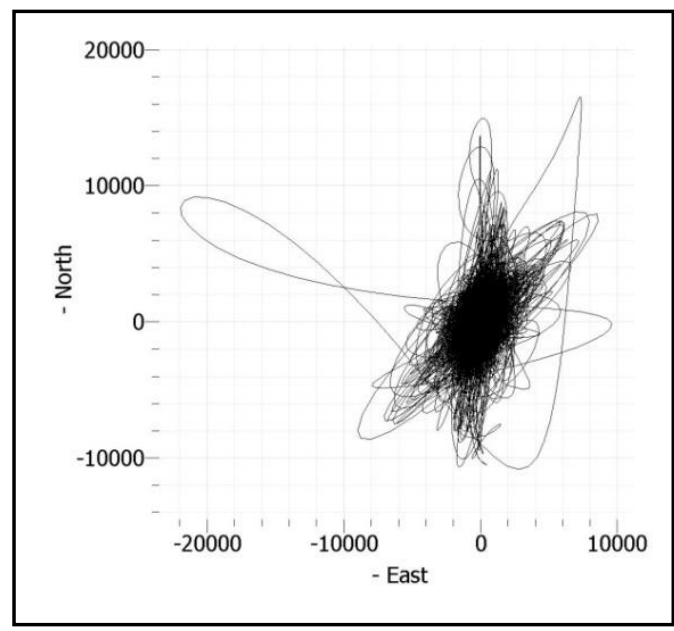

(2)

Gambar 10. Hasil analisa particle motion dengan geopsy pada titik pengukuran ke-8.

(1) Arah vertikal. (2) arah timur barat

Pada gambar 10 menunjukkan arah pergerakan partikel gelombang pada titik pengukuran yang ke-8. Pada gambar tersebut menunjukkan arah pergerakan partikel bergerak sejajar dengan bidang vertikal pada jembatan lebih dominan daripada ke arah utara selatan. Frekuensi arah pergerakan partikel tersebut tampak pada warna hitam yang dominan pada grafik vertikal.

\section{Kesimpulan}

Dari hasil dan pembahasan dapat disimpulkan sebagai berikut ini:

1. Densitas tangkasi pada beberapa tipe habitat ialah: hutan dataran tinggi 2,94 ekor/ha, pertanian 1,60 ekor/ha, mangrove 7,66 ekor/ha, dan semak 8,17 ekor/ha.

2. Ukuran densitas tangkasi menunjukan keamanan habitat sebagai lokasi persarangan dan mencari makan tangkasi. 


\section{Daftar Pustaka}

Anonimus. 2001. Spectral Tarsier (Tarsius spectrum). http://www.theprimata.com/tarsius_spectrum. html. Diakses tanggal 24 maret 2011

Anonim,

http://flickriver.com/search/tangkasi/.[15.03.2 013]

Gursky. S. 1998a. Conservation status of the spectral tarsier Tarsius spectrum: Population Density And Home Range Size. Folia Primatologica. Primate Taxonomy. Smithsonian Institution Press. Washington. 191 - 203 pp.

Gursky. S. 1998b. Sociality in the spectral tarsier. Tarsius spectrum. American Journal Primatology. United States. 89 - 101 pp.

Gursky, S. 2000. Effect of Seasonality on the Behavior of an Insectivorous Primate, Tarsius spectrum. Int. J. Primatol. 21 (3): 477-495

Gursky. S. 2006. Associations Between Adult Spectral Tarsiers. American Journal Of Physical Anthropology. Department of Anthropology, Texas Adan University, College Station, Texas. 74 - 83 pp.

Gursky, S., M. Shekelle, \& A. Nietsch. 2008. The Conservation Status of Indonesia's Tarsiers. Primates of The Oriental Night: 104-114.
Gursky. S. 2002. "Determinants Of gregariousness in the spectral tarsier (prosimian: Tarsius spectrum)". J. Zoological. 256 (3): 401-410.

Kinnaird MF. 1997. Sulawesi Utara: Sebuah Panduan Sejarah Alam. Jakarta: Percetakan Redikencana.

Noerdjito M, Maryanto I. 2001. Jenis-Jenis Hayati yang Dilindungi Perundang-Undangan Indonesia. Cibinong: Balitbang Zoologi, Puslitbang BiologiLIPI dan The Nature Conservancy.

Rewo. N. 1996. The Pictorial Guide to the Living Primates. Pogonias Press: East Hampton. New York.

Supriatna. J. dan Wahyono. E. H. 2000. Panduan Lapangan Primata Indonesia. Yayasan Obor Indonesia. Jakarta.

Shekelle. M. 2008. Distribution And Biogeography Of Tarsier. Primates of The Oriental Night. Indonesian Institute of Sciences Research Center For Biology. Cibinong. 13 - 27 pp.

Shekelle M., Colin G., Stefan M., and Jatna S. 2008. Tarsius tumpara: A New Tarsier Species from Siau Island, North Sulawesi. Primate Conservation Journal. 55 - 64 pp. 